\title{
St \\ A Study to Assess the Effect of Cholesterol Rich Diet on Sputum Status in Patients with Pulmonary Tuberculosis Admitted in a Selected Hospital of Mumbai
}

\author{
KIRTI M. JAMDAR
}

\section{Correspondence to :}

\section{KIRTI M. JAMDAR}

Department of S.N.D.T.

Women's University, L.T.

College of Nursing,

Churchgate, MUMBAI (M.S.)

INDIA

KEY WORDS :

Assess effect, Cholesterol rich

diet, Sputum

status, Pulmonary

tuberculosis,

Physiological

parameters
ABSTRACT : Effect of cholesterol rich diet on sputum status in patients with pulmonary tuberculosis admitted in a selected hospital of Mumbai. Quasi experimental approach was used. Sample: patients diagnosed with tuberculosis with sputum positive status. Tool: Cholesterol rich diet, observation checklist and daily dietary inventory. Nineteen patients out of 30 from the sample group had sputum conversion from positive to negative within one month period. The critical ratio was calculated which was 5.54 which showed a significant difference between the percentages of study and control group. There was also improvement in the client's general wellbeing. The activity level of the clients was also improved a lot. The cholesterol rich diet though was not effective in improving the patients' hemoglobin levels, W.B.C count but it helped in early sputum conversion of the clients. The cholesterol which was supplemented to the clients did not raise clients' cholesterol levels above normal. Thus, it was concluded that cholesterol rich diet could help in early sputum conversion in clients with tuberculosis. The study guides the nurse to plan for such cholesterol rich dietary supplementation for the patients. Health education can be provided to nurses and patients about cholesterol rich dietary supplementation. This study also helps the nurses to know about importance in planning and providing nutrition.

How to cite this paper : Jamdar, Kirti M. (2016). A Study to Assess the Effect of Cholesterol Rich Diet on Sputum Status in Patients with Pulmonary Tuberculosis Admitted in a Selected Hospital of Mumbai. Internat. J. Med. Sci., 9(1) : 10-14. 